\title{
Lower-Body Determinants of Running Economy in Male and Female Distance Runners
}

\author{
Kyle R. Barnes, ${ }^{1,2}$ Michael R. Mcguigan, ${ }^{1}$ and Andrew E. Kilding ${ }^{\mathbf{1}}$ \\ AU2 AU1 ${ }^{1}$ Sports Performance Research Institute Nerw Zealand, AUT University, Auckland, New Zealand; and ${ }^{2}$ Department of \\ Movement Science, Grand Valley State University, Allendale, Michigan
}

\begin{abstract}
Barnes, KR, Mcguigan, MR, and Kilding, AE. Lower-body determinants of running economy in male and female distance runners. J Strength Cond Res XX(X): 000-000, 2013-A variety of training approaches have been shown to improve running economy in well-trained athletes. However, there is a paucity of data exploring lower-body determinants that may affect running economy and account for differences that may exist between genders. Sixty-three male and female distance runners were assessed in the laboratory for a range of metabolic, biomechanical, and neuromuscular measures potentially related to running economy $\left(\mathrm{ml} \cdot \mathrm{kg}^{-1} \cdot \mathrm{min}^{-1}\right)$ at a range of running speeds. At all common test velocities, women were more economical than men (effect size $[E S]=0.40$ ); however, when compared in terms of relative intensity, men had better running economy $(E S=2.41)$. Leg stiffness $(r=-0.80)$ and moment arm length $(r=0.90)$ were large-extremely largely correlated with running economy and each other $(r=$ -0.82). Correlations between running economy and kinetic measures (peak force, peak power, and time to peak force) for both genders were unclear. The relationship in stride rate ( $r=-0.27$ to -0.31 ) was in the opposite direction to that of stride length $(r=0.32-0.49)$, and the relationship in contact time $(r=-0.21$ to -0.54$)$ was opposite of that of flight time ( $r$ $=0.06-0.74)$. Although both leg stiffness and moment arm length are highly related to running economy, it seems that no single lower-body measure can completely explain differences in running economy between individuals or genders. Running economy is therefore likely determined from the sum of influences from multiple lower-body attributes.
\end{abstract}

AU3 KEY WorDS submaximal aerobic capacity, neuromuscular characteristics, stiffness, moment arm, biomechanics, distance running

Address correspondence to Kyle R. Barnes, kyle.barnes@yahoo.com. $0(0) / 1-9$

Journal of Strength and Conditioning Research

(C) 2013 National Strength and Conditioning Association

\section{INTRODUCTION}

$\mathrm{R}$ unning economy is defined as the steady-state oxygen consumption $\left(\mathrm{V}_{2}\right)$ at a given running velocity (51); therefore, a lower $\mathrm{VO}_{2}$ at a given velocity would indicate better running economy. Runners with good running economy tend to run faster at a given distance or longer at a constant velocity than runners with poor running economy, assuming their $\dot{\mathrm{V}}_{2}$ max is the same. Despite the performance benefits of being an economical runner, researchers have yet to resolve why some runners demonstrate markedly better economy when compared with counterparts exhibiting similar fitness, training history, and performance backgrounds $(15,17,18,54)$.

A number of physiological, biomechanical, and neuromuscular factors seem to influence running economy in welltrained or elite runners. These include metabolic adaptations within the muscle such as increased mitochondria and oxidative enzymes (25), more efficient mechanics leading to less energy wasted on breaking forces and excessive vertical oscillation $(13,54)$, and the ability of muscles to store and release elastic energy by increasing the lower-body stiffness (16). Furthermore, a variety of modifiable (e.g., percent body fat, body mass) $(1,49)$ and unmodifiable (e.g., Achilles moment arm length, height, skeletal structure) $(1,50,52)$ anthropometric measures influence biomechanical and neuromuscular efficiency and subsequently alter running economy. For example, the amount of energy stored in a tendon depends on the mechanical properties of the tendon and on the force that stretch the tendon. Thus, for a given movement pattern, tendon force is inversely related to the moment arm of the Achilles tendon (52). Because it is generally accepted that storage and reutilization of elastic energy in tendons substantially reduce energy demands in running (10), previous research has been able to establish a relationship between the variation in running economy and the moment arm of the Achilles tendon $(50,52)$, albeit in small sample sizes of 8-15.

Recent research has focused on various neuromuscular or biomechanical characteristics as mechanisms to explain improvements in running economy (46,53). Any lower-body adaptations that allow for improved muscle power development, enhanced ability of the muscles to store and release elastic energy by increasing stiffness, or more efficient 
TABLE 1. Subject and training characteristics.*

\begin{tabular}{|c|c|c|c|c|c|c|c|}
\hline & $N$ & Age (y) & $\begin{array}{l}\text { Body mass } \\
\quad(\mathrm{kg})\end{array}$ & $\begin{array}{c}\dot{\mathrm{V}}_{2} \max \\
\left(\mathrm{ml} \cdot \mathrm{kg}^{-1} \cdot \mathrm{km}^{-1}\right)\end{array}$ & $\begin{array}{l}\text { Training history } \\
\text { (y) }\end{array}$ & $\begin{array}{l}\text { Training volume } \\
\left(\mathrm{km} \cdot \mathrm{wk}^{-1}\right)\end{array}$ & $\begin{array}{c}\text { Peak speed } \\
\left(\mathrm{km} \cdot \mathrm{h}^{-1}\right)\end{array}$ \\
\hline Men & 39 & $20.8 \pm 2.8$ & $67.8 \pm 6.8$ & $68.7 \pm 4.8$ & $6.9 \pm 2.9$ & $97.2 \pm 21.0$ & $21.1 \pm 1.6$ \\
\hline Women & 24 & $20.5 \pm 2.1$ & $55.0 \pm 5.5$ & $59.9 \pm 3.5$ & $6.9 \pm 2.1$ & $74.2 \pm 12.7$ & $19.4 \pm 1.2$ \\
\hline
\end{tabular}

*Values are given in mean $\pm S D$.

mechanics characterized by more skilled control of movement and muscle recruitment patterns $(1,5,32)$ could certainly explain differences in running economy among runners. The differences in running economy that exist between men and women have been previously investigated, but with mixed findings $(6,18,19,35,40,41)$. Research has yet to explore which of these lower-body characteristics can explain these interindividual differences in running economy between male and female trained distance runners. Therefore, this study was designed to evaluate the lower-body determinants of running economy among well-trained male and female distance runners.

\section{Methods}

\section{Experimental Approach to the Problem}

Male and female distance runners' physiological, biomechanical, and neuromuscular characteristics were assessed in our laboratory over a 3-year period. Testing took place during the competition phase of each runner's track or crosscountry seasons. Most athletes were tested on 1 or more occasions during this time span. When more than 1 set of data was available for any athlete, the mean of all tests was used to represent that athlete. Obtaining measures during the competition phase for a range of competitive runners enabled us to characterize the lower-body determinants or running economy at peak fitness levels. characteristics of the runners are presented in Table $1 . \quad$ T1 The study was approved by the Auckland University of Technology Ethics Committee, Auckland, New Zealand. All participants provided informed written consent to participate.

\section{Procedures}

Submaximal and Maximal Aerobic Measures. Each test session included a series of 4-minute submaximal runs on a motorized treadmill (PowerJog, Birmingham, United Kingdom) set at a $1.0 \%$ gradient until participants were clearly no longer able to sustain a steady-state $\dot{\mathrm{V}}_{2}\left(\mathrm{ml} \cdot \mathrm{kg}^{-1} \cdot \mathrm{min}^{-1}\right)$ (i.e., a slow component was evident), as determined visually from real-time plots of $\dot{\mathrm{V}}_{2}$ followed by a fixed speed incremental test to determine $\dot{\mathrm{VO}}_{2} \mathrm{max}$. Submaximal test velocities ranged from 12 to $18 \mathrm{~km} \cdot \mathrm{h}^{-1}$, and expired gases were measured continuously using a metabolic cart (ParvoMedics TrueOne 2400, Salt Lake City, UT, USA). Posttest data analysis revealed that the maximum velocity at which steady-state $\dot{\mathrm{V}}_{2}$ was achieved across the entire range of male and female subjects was $14 \mathrm{~km} \cdot \mathrm{h}^{-1}$ and was therefore used to make comparisons between genders. Running economy was defined as the mean $\dot{\mathrm{V}}_{2}$ determined during the last minute of each running speed and expressed in units relative to body mass and time $\left(\mathrm{ml} \cdot \mathrm{kg}^{-1} \cdot \mathrm{min}^{-1}\right)$. A lower $\dot{\mathrm{V}}_{2}$ at any given running velocity would be indicative of a better (or improved)

\section{Subjects}

Sixty-three runners were asAU4 sessed in our laboratory over a 3-year period. All runners competed at the collegiate or national level. The athletes were all well-trained distance runners competing in events ranging from $800 \mathrm{~m}$ to $10 \mathrm{~km}$ with 27 runners qualifying for national championships in cross-country, track or road races, winning 13 national titles and 5 competing at the international level over a 3-year testing period. Descriptive

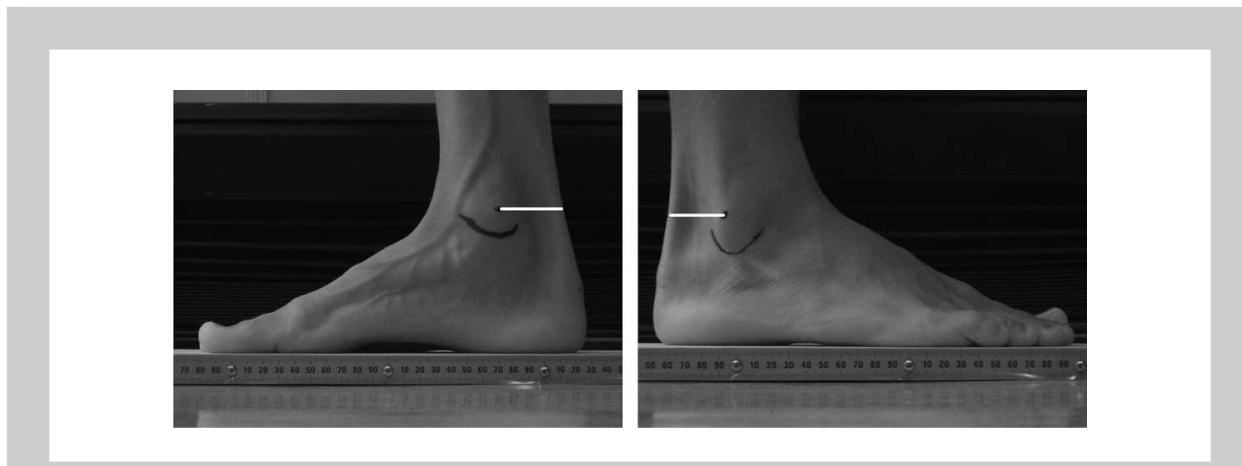

Figure 1. Standardized picture of the medial and lateral sides of the right foot, placed on, and aligned with a reference block. The horizontal distance from the medial and lateral malleolus to the Achilles tendon was determined (white lines). Moment arm was calculated as the mean of these 2 distances.

2 Journal of Strength and Conditioning Research" 
running economy. In our laboratory, the typical error of measurement of submaximal $\dot{\mathrm{V}}_{2}$ was $1.8 \%$ (3). Heart rate was determined every 1 second (Polar RS800sd; Polar Electro,

AU5 Finland). Approximately 2 minutes after the last submaximal run, the incremental test was performed using a velocity of $1.0 \mathrm{~km} \cdot \mathrm{h}^{-1}$ below each participants' final submaximal run speed. Treadmill gradient was increased by $1 \%$ each minute until volitional exhaustion. The highest $\dot{\mathrm{V}}_{2}$ over a 30 -second period during the test was considered $\mathrm{V}_{2}$ max. Endurance performance was indicated by the peak running speed reached at the end of the incremental treadmill test. Because we used increases in gradient (rather than speed) in the latter part of the treadmill test, we calculated speed on the flat as $S=S_{\mathrm{T}}+\left(S_{\mathrm{T}} \times 0.045\right) \times i$, where $S$ is the peak speed in $\mathrm{km} \cdot \mathrm{h}^{-1}, S_{\mathrm{T}}$ is the treadmill speed in $\mathrm{km} \cdot \mathrm{h}^{-1}$, and $i$ is the treadmill inclination in percent (7). Biomechanical measures (stride rate, stride length, contact time, and flight time) were determined using high-speed video analysis during treadmill testing.

Neuromuscular Measures. After the submaximal and maximal aerobic measures, participants performed a series of jump tests (countermovement jump [CMJ], squat jump [SJ], and 5 -jump plyometric test [5J] involving 5 continuous vertical straight-leg jumps in which subjects were instructed to aim for maximal height with contact times as short as possible, keeping legs straight and arms still throughout the jumping sequence) on an AccuPower force plate (Advanced Mechanical Technology, Inc., Watertown, MA, USA) to determine neuromuscular characteristics previously described in the literature $(37,53)$. The following parameters were determined for each type of jump: peak force, time to peak force, peak power, and displacement. Eccentric utilization ratio (EUR) and stiffness were also calculated from the aforementioned parameters. Eccentric utilization ratio is an indicator of stretch-shortening cycle ability in a variety of sports and during different phases of training (37). The EUR was calculated as the peak power ratio between performance on the CMJ compared with the SJ (37). Stiffness was estimated by dividing the relative peak force $\left(\mathrm{N} \cdot \mathrm{kg}^{-1}\right)$ by the vertical displacement $(\mathrm{m})$ measured during the $5 \mathrm{~J}$ as previously described by Cavagna et al. (9).

Moment Arm of the Achilles Tendon. Methods for measuring the moment arm of the Achilles tendon followed those of Scholz et al. (52). Briefly, we marked the most prominent aspect of the tip of the medial and lateral malleoli and took standardized photographs (Casio Exilim Pro Ex-F1; Casio Computer Co., Shelton, CT, USA) of the medial and lateral sides of the foot while aligned with the reference block

F1 (Figure 1). The horizontal distance from the marked spot to the posterior aspect of the Achilles tendon was determined on the picture. The moment arm was taken to be the mean of these 2 distances.

\section{Statistical Analyses}

Pearson's product moment correlation coefficient was used to determine relationships between running economy and functional lower-body measures using SPSS (IBM SPSS version 19.0; Chicago, IL, USA). Resulting correlation coefficients were converted into $90 \%$ confidence limits using a spreadsheet (27). The threshold values for small, moderate, large, very large, and extremely large magnitudes were, respectively, $0.1,0.3,0.5,0.7$, and 0.9 of the correlation coefficient. The relationship between running economy and Achilles tendon moment arm was fitted with a nonlinear model of the form $y=\mathrm{a} x^{-2}+\mathrm{b}$, following Scholz et al. (52), which corresponds to the model of spring mechanics (assuming a linear spring where $n=1$ ) previously shown to predict running economy in humans $(50,52)$. Comparisons of the differences between genders were made using a spreadsheet to calculate effect size (ES), and the magnitude of differences were evaluated nonclinically (29): if the confidence interval overlapped thresholds for substantial positive and negative values $( \pm 0.20$ standardized units, i.e., 0.20 of the between-subject $S D$ of the dependent in the pretest), the effect was deemed unclear; all other effects were reported as the magnitude of the observed value and were evaluated probabilistically with threshold values of $0.20,0.60,1.2,2.0$,

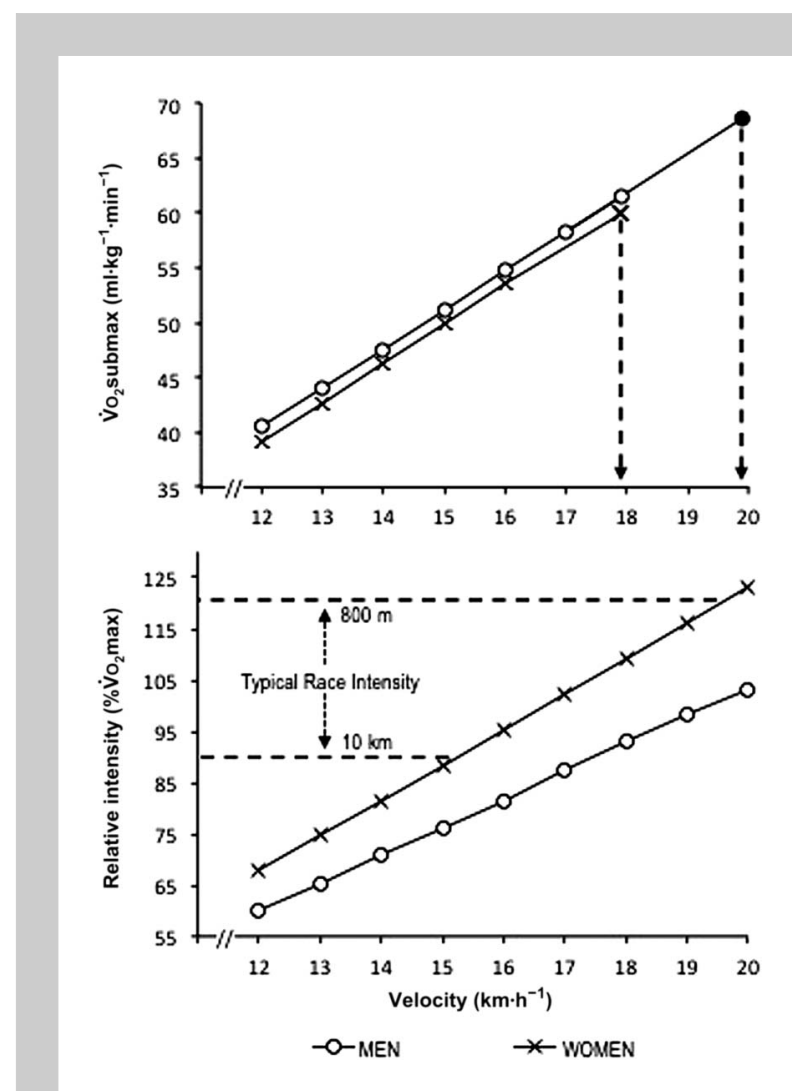

Figure 2. Aerobic profiles of male $(n=39)$ and female $(n=24)$ runners expressed in terms of relative $\mathrm{O}_{2}$ consumption $\left(\mathrm{V}_{2}\right.$ submax) and relative intensity. Bold $\times$ and $\bullet$ indicate velocity at $\mathrm{V}_{2} \max \left(\mathrm{vV}_{2} \max \right)$. 
and 4.0 for small, moderate, large, very large, and extremely large, respectively $(28,29)$. The probabilities were reported qualitatively using the following scale: $25-75 \%$, possibly; $75-$ 95\%, likely; 95-99.5\%, very likely; and $>99.5 \%$, most likely (29).

\section{RESUlts}

Descriptive characteristics of the runners are presented in Table 1 . There was no difference between men and women in age or training history, a large difference in training volume and peak speed and very large difference between body mass, and $\dot{\mathrm{V}}_{2}$ max.

Aerobic profiles generated from the mean economy curves of male and female runners are shown in Figure 2. At all common test velocities, women were more economical than men $(p=0.13, \mathrm{ES}=0.40)$. However, the combination of a very large difference in $\dot{\mathrm{V}}_{2} \max (p<0.001$, ES $=$ $2.95)$ and similar economy slopes resulted in a large difference $(p<0.001, \mathrm{ES}=1.91)$ in $\mathrm{v}^{\mathrm{VO}_{2}}$ max. When men and

TABLE 2. Mean male and female biomechanical and neuromuscular outcome measures and statistics for effects and inferences between genders.

\begin{tabular}{|c|c|c|c|c|}
\hline & \multirow[b]{2}{*}{$\begin{array}{l}\text { Men }(n=39) \\
(\text { mean } \pm S D)\end{array}$} & \multirow[b]{2}{*}{$\begin{array}{l}\text { Women }(n=24) \\
\quad(\text { mean } \pm S D)\end{array}$} & \multicolumn{2}{|c|}{ Group comparison (men-women) } \\
\hline & & & $\begin{array}{c}\text { Difference between groups }( \pm 90 \% \\
\text { confidence limit) }\end{array}$ & $\begin{array}{c}\text { Qualitative } \\
\text { inference }(E S)^{*}\end{array}$ \\
\hline \multicolumn{5}{|l|}{$\begin{array}{l}\text { Biomechanical } \\
\text { measures }\end{array}$} \\
\hline $\begin{array}{l}\text { Stride rate (strides } \\
\text { per minute) }\end{array}$ & $85.6 \pm 4.8$ & $90.2 \pm 4.5$ & $5.4 \pm 2.3$ & Moderate $\ddagger(0.97)$ \\
\hline Stride length (m) & $2.89 \pm 0.21$ & $2.66 \pm 0.21$ & $-8.0 \pm 3.3$ & Moderate§ (1.10) \\
\hline Contact time (s) & $0.23 \pm 0.02$ & $0.24 \pm 0.02$ & $2.9 \pm 3.5$ & Small $\dagger(0.36)$ \\
\hline Flight time (s) & $0.12 \pm 0.02$ & $0.10 \pm 0.02$ & $-20.5 \pm 8.3$ & Large $\dagger(1.29)$ \\
\hline Moment arm (cm) & $4.4 \pm 0.6$ & $3.5 \pm 0.5$ & $21.6 \pm 6.1$ & Large§ $(1.78)$ \\
\hline \multicolumn{5}{|l|}{$\begin{array}{l}\text { Neuromuscular } \\
\text { measures }\end{array}$} \\
\hline EUR & $1.01 \pm 0.06$ & $1.02 \pm 0.12$ & $0.0 \pm 4.3$ & Unclear $(0.00)$ \\
\hline Stiffness $\left(\mathrm{kN} \cdot \mathrm{m}^{-1}\right)$ & $9.4 \pm 2.2$ & $13.3 \pm 2.7$ & $41.3 \pm 10.9$ & Large $\dagger(1.44)$ \\
\hline Jump height $(\mathrm{m})$ & $0.49 \pm 0.14$ & $0.30 \pm 0.10$ & $-39.2 \pm 13.7$ & Large§ (1.67) \\
\hline $\begin{array}{l}\text { Countermovement } \\
\text { jump }\end{array}$ & & & & \\
\hline $\begin{array}{l}\text { Peak force } \\
\left(\mathrm{N} \cdot \mathrm{kg}^{-1}\right)\end{array}$ & $61.6 \pm 15.3$ & $61.3 \pm 14.6$ & $-0.3 \pm 10.5$ & Unclear $(0.01)$ \\
\hline $\begin{array}{l}\text { Peak power } \\
\left(\mathrm{W} \cdot \mathrm{kg}^{-1}\right)\end{array}$ & $45.1 \pm 5.4$ & $38.0 \pm 5.8$ & $-16.2 \pm 6.5$ & Large $\dagger(1.24)$ \\
\hline $\begin{array}{l}\text { Time to peak } \\
\text { force }(s)\end{array}$ & $2.19 \pm 0.52$ & $2.16 \pm 0.42$ & $0.6 \pm 9.1$ & Unclear (0.03) \\
\hline \multicolumn{5}{|l|}{ Squat jump } \\
\hline $\begin{array}{l}\text { Peak force } \\
\left(\mathrm{N} \cdot \mathrm{kg}^{-1}\right)\end{array}$ & $57.2 \pm 11.9$ & $52.9 \pm 11.2$ & $-7.9 \pm 9.8$ & Small $\ddagger(0.38)$ \\
\hline $\begin{array}{l}\text { Peak power } \\
\left(\mathrm{W} \cdot \mathrm{kg}^{-1}\right)\end{array}$ & $44.8 \pm 5.1$ & $37.6 \pm 5.0$ & $-16.2 \pm 5.7$ & Large $\ddagger(1.40)$ \\
\hline $\begin{array}{l}\text { Time to peak } \\
\text { force }(s)\end{array}$ & $2.60 \pm 0.60$ & $2.24 \pm 0.38$ & $-12.4 \pm 9.5$ & Moderate $\dagger(0.60)$ \\
\hline \multicolumn{5}{|l|}{ 5-Jump test } \\
\hline $\begin{array}{l}\text { Peak force } \\
\left(\mathrm{N} \cdot \mathrm{kg}^{-1}\right)\end{array}$ & $64.9 \pm 9.2$ & $68.4 \pm 11.1$ & $5.0 \pm 7.2$ & Small $\dagger(0.31)$ \\
\hline $\begin{array}{l}\text { Peak power } \\
\left(\mathrm{W} \cdot \mathrm{kg}^{-1}\right)\end{array}$ & $68.9 \pm 16.5$ & $51.8 \pm 10.7$ & $-24.2 \pm 10.5$ & Moderate§ (1.16) \\
\hline $\begin{array}{l}\text { Time to peak } \\
\text { force }(s)\end{array}$ & $3.23 \pm 0.72$ & $2.68 \pm 0.52$ & $-16.5 \pm 9.4$ & 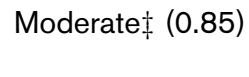 \\
\hline
\end{tabular}

${ }^{\star} \mathrm{ES}=$ effect size; $\mathrm{EUR}=$ eccentric utilization ratio.

$\uparrow 25-75 \%$, possible.

$\$ 75-95 \%$, likely.

$\$ 95-99.5 \%$, very likely.

$\|>99.5 \%$, most (or extremely) likely.

$\pi<0.2$ trivial; $\geq 0.2$ small; $\geq 0.6$ moderate; $\geq 1.2$ large; $\geq 2.0$ very large; $\geq 4.0$ extremely large.

$4 \quad$ Journal of Strength and Conditioning Research 
women were compared in terms of relative intensity at common running velocities (Figure 2), men ran at a significantly lower percentage of their respective $\dot{\mathrm{V}}_{2} \max (p<0.001$, $\mathrm{ES}=2.41$ ).

T2 Table 2 shows the mean male and female outcome measures and magnitude of differences between genders. Women took moderately more strides per minute and had moderately shorter stride length and longer contact times and shorter flight times. There were large differences in Achilles moment arm length, stiffness, and jump height (Table 2) between genders. Men produced greater peak force and peak power than women, and the differences were of small and large magnitude, respectively. There were no clear differences in CMJ peak force between genders. Women's time to peak force was moderately faster than men, except in the
$\mathrm{CMJ}$ measure, which was unclear. Differences in EUR were unclear.

The correlations between running economy and lowerbody characteristics for male and female runners are provided in Table 3. Generally, the relationship among biomechanical measures was small-moderate in men, except flight time that was unclear and moderate-large in women. For men and women, the relationship in stride rate (negative) was in the opposite direction to that of stride length (positive), and the relationship in contact time (negative) was opposite of that of flight time (positive). There was a large positive relationship between running economy and moment arm length in both male and female runners (Table $3)$; and this relationship was stronger (extremely large) when these data were combined $(r=0.90 ; 90 \%$ confidence limit,

TABLE 3. Correlations between running economy $\left(\mathrm{ml} \cdot \mathrm{kg}^{-1} \cdot \mathrm{min}^{-1}\right)$ and lower-body characteristics in male and female distance runners.

\begin{tabular}{|c|c|c|c|c|}
\hline & \multicolumn{2}{|c|}{ Men $(n=39)$} & \multicolumn{2}{|c|}{ Women $(n=24)$} \\
\hline & $\begin{array}{l}\text { Correlation with } \pm 90 \% \\
\quad \text { confidence limit }\end{array}$ & $\begin{array}{l}\text { Qualitative } \\
\text { inference }\end{array}$ & $\begin{array}{l}\text { Correlation with } \pm 90 \% \\
\quad \text { confidence limit }\end{array}$ & $\begin{array}{l}\text { Qualitative } \\
\text { inference }\end{array}$ \\
\hline \multicolumn{5}{|l|}{ Biomechanical measures } \\
\hline $\begin{array}{l}\text { Stride rate (strides } \\
\text { per minute) }\end{array}$ & $-0.27 \pm 0.25$ & $-v e \dagger$ & $-0.31 \pm 0.31$ & $-v e \dagger$ \\
\hline Stride length $(\mathrm{m})$ & $0.32 \pm 0.24$ & $+\mathrm{ve} \dagger$ & $0.49 \pm 0.19$ & +ve§ \\
\hline Contact time (s) & $-0.21 \pm 0.26$ & $-v e^{\star}$ & $-0.54 \pm 0.25$ & $-v e \dagger$ \\
\hline Flight time $(\mathrm{s})$ & $0.06 \pm 0.27$ & Unclear & $0.74 \pm 0.17$ & $+v e \S$ \\
\hline Moment arm $(\mathrm{cm})$ & $0.82 \pm 0.09$ & +ve§ & $0.81 \pm 0.13$ & tve§ \\
\hline \multicolumn{5}{|l|}{$\begin{array}{l}\text { Neuromuscular } \\
\text { measures }\end{array}$} \\
\hline EUR & $0.04 \pm 0.27$ & Unclear & $-0.02 \pm 0.34$ & Unclear \\
\hline Stiffness $\left(\mathrm{kN} \cdot \mathrm{m}^{-1}\right)$ & $-0.57 \pm 0.19$ & $-v e \S$ & $-0.76 \pm 0.16$ & -ve§ \\
\hline Jump height $(m)$ & $0.39 \pm 0.23$ & $+v e \ddagger$ & $0.66 \pm 0.21$ & +ve§ \\
\hline \multicolumn{5}{|l|}{$\begin{array}{l}\text { Countermovement } \\
\text { jump }\end{array}$} \\
\hline Peak force $\left(\mathrm{N} \cdot \mathrm{kg}^{-1}\right)$ & $-0.14 \pm 0.37$ & Unclear & $0.05 \pm 0.34$ & Unclear \\
\hline $\begin{array}{l}\text { Peak power } \\
\left(\mathrm{W} \cdot \mathrm{kg}^{-1}\right)\end{array}$ & $-0.14 \pm 0.37$ & Unclear & $0.28 \pm 0.32$ & $+v e \dagger$ \\
\hline Time to peak force & $0.21 \pm 0.26$ & $+v e^{*}$ & $0.20 \pm 0.33$ & Unclear \\
\hline \multicolumn{5}{|l|}{ Squat jump } \\
\hline Peak force $\left(\mathrm{N} \cdot \mathrm{kg}^{-1}\right)$ & $0.28 \pm 0.25$ & $+v e \dagger$ & $0.03 \pm 0.34$ & Unclear \\
\hline $\begin{array}{l}\text { Peak power } \\
\left(\mathrm{W} \cdot \mathrm{kg}^{-1}\right)\end{array}$ & $-0.04 \pm 0.27$ & Unclear & $0.38 \pm 0.30$ & $+v e \dagger$ \\
\hline Time to peak force & $0.17 \pm 0.26$ & Unclear & $0.16 \pm 0.34$ & Unclear \\
\hline \multicolumn{5}{|l|}{ 5-Jump test } \\
\hline Peak force $\left(\mathrm{N} \cdot \mathrm{kg}^{-1}\right)$ & $-0.19 \pm 0.26$ & $-v e^{*}$ & $-0.03 \pm 0.34$ & Unclear \\
\hline $\begin{array}{l}\text { Peak power } \\
\left(\mathrm{W} \cdot \mathrm{kg}^{-1}\right)\end{array}$ & $-0.06 \pm 0.27$ & Unclear & $0.59 \pm 0.24$ & +ve§ \\
\hline Time to peak force & $0.05 \pm 0.27$ & Unclear & $0.16 \pm 0.34$ & Unclear \\
\hline \multicolumn{5}{|c|}{$\begin{array}{l}* 25-75 \% \text {, possible. } \\
\nmid 75-95 \% \text {, likely. } \\
+95-99.5 \% \text {, very likely. } \\
\S>99.5 \% \text {, most (or extremely) likely. } \\
\|<0.0 \text { trivial; } \geq 0.1 \text { small; } \geq 0.3 \text { moderate; } \geq 0.5 \text { large; } \geq 0.7 \text { very large; } \geq 0.9 \text { extremely large; } 1.0 \text { perfect. }\end{array}$} \\
\hline
\end{tabular}




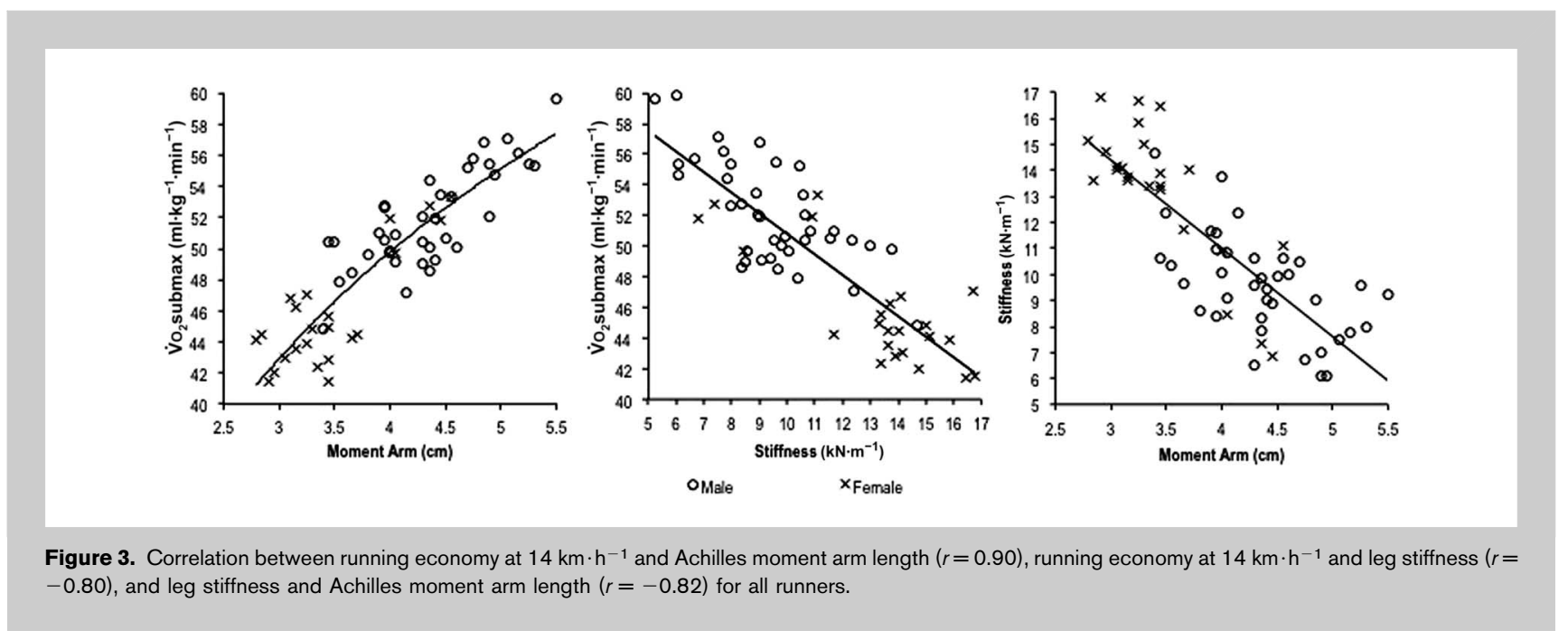

AU6 F3 0.85 to 0.93; Figure 3). All relationships between EUR and running economy were unclear. There was a moderate and large negative correlation between muscle stiffness and running economy (Table 3 ) in men and women, respectively. This relationship was slightly higher when male and female data were combined $(r=-0.80 ; 90 \%$ confidence limit, -0.86 to -0.71 ; Figure 3 ). Muscle stiffness was also largely negatively related to moment arm length $(r=-0.82 ; 90 \%$ confidence limit, -0.88 to -0.74 ; Figure 3 ). There were moderate and large correlations between running economy and jump height in men and women, respectively. Most other correlations between running economy and jumprelated measures (peak force, peak power, and time to peak force) for men and women were unclear (Table 3).

\section{Discussion}

In this study, we compared specific anthropometric, neuromuscular, and biomechanical lower-body measures and explored relationships between measures in a large sample of well-trained male and female distance runners in an attempt to identify key determinants of running economy. Athletes such as distance runners rely on efficient utilization of available energy to facilitate optimum performance. The results of this investigation suggest that differences in running economy between distance runners seem in part to be the result of select modifiable and nonmodifiable lower-body characteristics, which may also explain differences in performance.

AU7 It is well known that stiffer muscles, or tendons, are more economical at transferring energy $(10,16,34,53)$. The stiffness values in our 63 well-trained runners (male, $9.4 \mathrm{kN} \cdot \mathrm{m}^{-1}$; female, $13.3 \mathrm{kN} \cdot \mathrm{m}^{-1}$ ) were similar to those of Dumke et al. (20) $\left(11.8 \mathrm{kN} \cdot \mathrm{m}^{-1}\right)$ and Fukashiro et al. (22) (9.6 $\mathrm{kN} \cdot \mathrm{m}^{-1}$ ) using well-trained and untrained men and women, respectively. Similar to other studies $(2,20)$, the present data demonstrated that lower-body stiffness is substantially related to running economy of well-trained runners (Table 3 ; Figure 3). Although it remains to be determined the trainability of stiffness across varying levels of fitness, emerging evidence suggests that runners and coaches may want to focus on strategies to improve lower-body stiffness to enhance performance. Indeed, previous evidence has also shown that running economy is strongly related to performance times at distances $>800 \mathrm{~m}(15,39)$. This study also showed that lower-body stiffness was related to the moment arm of the Achilles tendon (Figure 3). This is a unique finding not previously reported in the literature and suggests that the Achilles moment arm may affect stiffness properties after training. The relationship between resistance training and/or AU8 plyometric training and running economy is not a new concept. In fact, several research investigations have shown that strength training (both high resistance and explosive) can improve running economy by modulating lower-body stiffness $(3,46,53)$.

Our data revealed a substantial relationship between running economy and the moment arm of the Achilles tendon. This relationship was anticipated based on a simple musculoskeletal model of tendon energy storage (52), but the magnitude of this relationship $(r=0.90$; Figure 3$)$ was considerably larger than previously reported by Raichlen et al. $(r=0.64, n=8)(50)$ and Scholz et al. $(r=0.77, n=$ 15). This finding supports the premise that storage and release of elastic strain energy in the Achilles tendon plays an important role in reducing the energy cost of running. This spring-like action of the Achilles tendon during running means that individuals with smaller (shorter) moment arms stretch their Achilles tendons to a greater degree and therefore convert a higher percentage of kinetic energy into elastic energy, which is then returned to the propulsive forces of the stance leg. The energy generated by the contractile machinery of the lower body is metabolically the most expensive process in muscle contraction (52); thus, any

6 Journal of Strength and Conditioning Research 
energy stored in the tendon that does not have to be generated during muscle contraction results in a lower energy cost of running. Previous research indicates that variations in moment arm explained 56\% (52) and 64\% (50) of the variation in running economy among runners. Although Achilles moment arm length is a nonmodifiable factor affecting running economy, for practitioners, this is an easy determinant to measure and may help scientists and coaches understand why some athletes have good or poor economy and may also be a determinant of the upper and lower limits of an individual's ability to improve their running economy.

The findings from previous studies suggest that neuromuscular characteristics may play an important role in running economy, especially in athletes with similar physiological attributes $(5,31,46)$. However, our results suggest that most neuromuscular characteristics, at least those measured in this study, have an unclear or small relationship with running economy. In previous studies, the timing and amplitude of muscle activity has shown the most consistent association with running economy $(16,33,44,47,48)$. Measurements of electromyographic muscle activity were beyond the scope of this study, but on greater inspection, most of the previous studies indicate that greater muscle activity before and in the initial phase of ground contact may enhance running economy by increasing leg stiffness and maximizing exploitation of stored elastic energy. Leg stiffness is modulated by neuromuscular activation, and changes in stiffness have been shown to occur as a result of neuromuscular adaptation to training (21). It has been suggested that if the rate of force development and peak force is enhanced, a longer recovery period between muscle contraction is possible, leading to improved muscle blood perfusion and thereby improving running economy $(23,45)$. Other authors suggest that the ability of the neuromuscular system to repeatedly produce force rapidly may be an important determinant of running economy (48). Direct evidence to support this premise is limited and weak and although many of our lower-body determinants were indirect measures of neuromuscular activity, we found no such relationships between these measures and running economy suggesting future research should concentrate on more direct measures of neuromuscular activity and running economy. Until more data are collected, coaches and athletes should focus on interventions that increase lower-body stiffness.

The results of previous studies have identified a number of biomechanical variables that relate to running economy, including stride length that is freely chosen $(11,13,14,38,42,54)$, low vertical oscillation of body center of mass $(13,54)$, and low peak ground reaction forces $(54,55)$. In this study, we considered the basic biomechanical characteristics most often reported in the literature. Stride length was moderately correlated with running economy in this study. Relationships between running economy and stride length, expressed as an absolute or relative to height or leg length, have also been low to moderate $(13,14,54)$.
The most striking and ubiquitous finding regarding stride length and running is that a freely chosen stride length is most economical $(12,24,38,42,55)$. Experimentally induced deviations from this freely chosen stride length have invariably evoked increased oxygen cost $(14,24)$. There is a natural reciprocal relationship between stride length and stride rate, suggesting that runners naturally acquire an optimal stride rate based on perceived exertion (14). It is not surprising then that stride rate was also small-moderately correlated with running economy. The balance between the time during which the foot is in contact with the ground (contact time) and not in contact with the ground (flight time) has been studied in relation to running economy, but with no consistent findings. Likewise, we found small correlation between contact time and running economy in men and a large correlation in women; furthermore, there was no correlation between flight time and running economy in men, but very large correlation in women. Previous studies completed have found that longer contact times and shorter flight times were associated with poorer economy (54), which our female results support, whereas others have found the opposite relationship (43), and others no relationship $(13,55)$, which our male results support. There is an intuitive AU9 link between running mechanics and energy cost of running, but research to date has not established a clear mechanical profile of an economical runner. The results of this study corroborate this statement. It seems that through training, individuals are able to integrate and accommodate their own unique combination of dimensions and mechanical characteristics so that they arrive at a running motion that is most economical for them.

Our running economy data, shown in Figure 2, are in disagreement with some $(4,6,17,30)$ but not all $(8,19,26,35,36)$ previous investigations demonstrating that men are more economical than women when compared at common running velocities. However, when compared in terms of relative intensity, men ran at a significantly lower percentage of their respective $\dot{\mathrm{V}}_{2}$ max compared with women (Figure 2). The comparison in terms of relative intensity is an important one because well-trained runners all perform at near equal percentages of their respective $\dot{\mathrm{V}}_{2}$ max depending on the distance of the event in question (17). Figure 2 presents these findings and demonstrates that the magnitude of differences between genders is greater as the intensity of the competitive event increases. In an attempt to elucidate any gender differences in running economy, our comparison of the lowerbody determinants of running economy (Table 2) revealed substantial differences in biomechanical measures. Williams et al. (55) also showed that women were biomechanically different than men during running by demonstrating that woman possess greater stride rates and shorter stride lengths compared with male counterparts. In this study, men demonstrated greater peak force and peak power when normalized by body mass, whereas women have a faster time to peak force. This supports the finding that women have 
a substantially faster stride rate and short stride length. The increased energy costs from a higher stride rate because of various kinetic and kinematic patterns involved in a faster gait cycle may be an explanation for why in some studies women are less economical than male runners.

In summary, despite some substantial correlations between some lower-body measures and running economy, it seems that no single lower-body measure can completely explain differences in running economy within and between genders. Other factors such as body lengths, mass distribution, fiber type, vertical oscillation, footstrike patterns, and other kinetic and kinematics are also likely to affect running economy. Running economy is therefore likely determined from the sum of influences from multiple lower-body attributes.

\section{Practical Applications}

Many of the lower-body characteristics measured in this study represent specific or independent qualities of running economy that can be assessed and trained independently. Given the strong relationship between running economy and stiffness as indicated by our results, perhaps a greater efficiency of training can be achieved by targeting interventions that increase leg stiffness to improve running economy. The Achilles moment arm length is a nonmodifiable determinant related to running economy and seems to provide the practitioner with information about the stiffness of the lower body, which may elucidate an athlete's potential to improve their running economy, however more data are needed to validate this. The data we have presented here for a variety of lower-body measures commonly measured in athletes give an indication of normative ranges for welltrained male and female runners.

\section{ACKNowledgments}

The authors would like to thank the subjects for their participation. The authors have no professional relationship with a for-profit organization that would benefit from this study and no financial assistance with the project was received.

\section{REFERENCES}

1. Anderson, T. Biomechanics and running economy. Sports Med 22: 76-89, 1996.

2. Arampatzis, A, De Monte, G, Karamanidis, K, Morey-Klapsing, G, Stafilidis, S, and Bruggemann, GP. Influence of the muscle-tendon unit's mechanical and morphological properties on running economy. J Exp Biol 209: 3345-3357, 2006.

3. Barnes, KR, Hopkins, WG, McGuigan, MR, Northuis, ME, and Kilding, AE. Effects of resistance training on running economy and cross-country performance. Med Sci Sports Exerc 2013. In press.

4. Bhambani, Y and Singh, M. Metabolic and cinematographic analysis of walking and running in men and women. Med Sci Sports Exerc 17: 131-137, 1985

5. Bonacci, J, Chapman, A, Blanch, P, and Vicenzino, B. Neuromuscular adaptations to training, injury and passive interventions: Implications for running economy. Sports Med 39: 903-921, 2009.

8 Journal of Strength and Conditioning Research
6. Bransford, DR and Howley, ET. Oxygen cost of running in trained and untrained men and women. Med Sci Sports 9: 41-44, 1977.

7. Brooks, GA, Fahey, TD, and White, TP. Exercise Physiology: Human Bioenergetics and its Applications. Mountain View, CA: Mayfield Pub. Co., 1996.

8. Bunc, V and Heller, J. Energy cost of running in similarly trained men and women. Eur J Appl Physiol Occuo Physiol 59: 178-183, 1989.

9. Cavagna, GA, Franzetti, P, Heglund, NC, and Willems, P. The determinants of the step frequency in running, trotting and hopping in man and other vertebrates. J Physiol 399: 81-92, 1988.

10. Cavagna, GA and Kaneko, M. Mechanical work and efficiency in level walking and running. J Physiol 268: 467-481, 1977.

11. Cavagna, GA, Willems, PA, Franzetti, P, and Detrembleur, C. The two power limits conditioning step frequency in human running. J Physiol 437: 95-108, 1991.

12. Cavanagh, PR and Kram, R. The efficiency of human movement-A statement of the problem. Med Sci Sports Exerc 17: 304-308, 1985.

13. Cavanagh, PR, Pollock, ML, and Landa, J. A biomechanical comparison of elite and good distance runners. Ann $N$ Y Acad Sci 301: 328-345, 1977

14. Cavanagh, PR and Williams, KR. The effect of stride length variation on oxygen uptake during distance running. Med Sci Sports Exerc 14: 30-35, 1982.

15. Conley, DL and Krahenbuhl, GS. Running economy and distance running performance of highly trained athletes. Med Sci Sports Exerc 12: 357-360, 1980 .

16. Dalleau, G, Belli, A, Bourdin, M, and Lacour, JR. The spring-mass model and the energy cost of treadmill running. Eur J Appl Physiol Occuo Physiol 77: 257-263, 1998.

17. Daniels, JT and Daniels, N. Running economy of elite male and elite female runners. Med Sci Sports Exerc 24: 483-489, 1992.

18. Daniels, JT, Krahenbuhl, G, Foster, C, Gilbert, J, and Daniels, S. Aerobic responses of female distance runners to submaximal and maximal exercise. Ann N Y Acad Sci 301: 726-733, 1977.

19. Davies, CT and Thompson, MW. Aerobic performance of female marathon and male ultramarathon athletes. Eur J Appl Physiol Occuo Physiol 41: 233-245, 1979.

20. Dumke, CL, Pfaffenroth, CM, McBride, JM, and McCauley, GO. Relationship between muscle strength, power and stiffness and running economy in trained male runners. Int J Sports Physiol Perform 5: 249-261, 2010.

21. Franklin, DW, Burdet, E, Osu, R, Kawato, M, and Milner, TE. Functional significance of stiffness in adaptation of multijoint arm movements to stable and unstable dynamics. Exp Brain Res 151: $145-157,2003$

22. Fukashiro, S, Noda, M, and Shibayama, A. In vivo determination of muscle viscoelasticity in the human leg. Acta Physiol Scand 172: 241248, 2001.

23. Hoff, J, Helgerud, J, and Wisloff, U. Maximal strength training improves work economy in trained female cross-country skiers. Med Sci Sports Exerc 31: 870-877, 1999.

24. Hogberg, P. How do stride length and stride frequency influence the energy-output during running? Arbeitsphysiologie 14: 437-441, 1952.

25. Holloszy, JO, Rennie, MJ, Hickson, RC, Conlee, RK, and Hagberg, JM. Physiological consequences of the biochemical adaptations to endurance exercise. Ann N Y Acad Sci 301: 440-450, 1977.

26. Hopkins, $\mathrm{P}$ and Powers, SK. Oxygen uptake during submaximal running in highly trained men and women. Am Correct Ther J 36: 130-132, 1982.

27. Hopkins, WG. A spreadsheet for deriving a confidence interval, mechanistic inference and clinical inference from a $\mathrm{p}$ value. Sportscience 11: 16-20, 2007.

28. Hopkins, WG. A spreadsheet to compare means of two groups. Sportscience 11: 22-23, 2007. 
29. Hopkins, WG, Marshall, SW, Batterham, AM, and Hanin, J. Progressive statistics for studies in sports medicine and exercise science. Med Sci Sports Exerc 41: 3-13, 2009.

30. Howley, ET and Glover, ME. The caloric costs of running and walking one mile for men and women. Med Sci Sports 6: 235-237, 1974.

31. Johnston, R, Quinn, T, Kertzer, R, and Vroman, N. Strength training in female distance runners: Impact on running economy. $J$ Strength Cond Res 11: 224-229, 1997.

32. Jung, AP. The impact of resistance training on distance running performance. Sports Med 33: 539-552, 2003

33. Kyrolainen, H, Belli, A, and Komi, PV. Biomechanical factors affecting running economy. Med Sci Sports Exerc 33: 1330-1337, 2001.

34. Lichtwark, GA and Wilson, AM. Optimal muscle fascicle length and tendon stiffness for maximising gastrocnemius efficiency during human walking and running. J Theor Biol 252: 662-673, 2008.

35. Maughan, RJ and Leiper, JB. Aerobic capacity and fractional utilisation of aerobic capacity in elite and non-elite male and female marathon runners. Eur J Appl Physiol Occup Physiol 52: 8087,1983

36. Mayhew, JL, Piper, FC, and Etheridge, GL. Oxygen cost and energy requirement of running in trained and untrained males and females. J Sports Med Phys Fitness 19: 39-44, 1979.

37. McGuigan, MR, Doyle, TL, Newton, M, Edwards, DJ, Nimphius, S and Newton, RU. Eccentric utilization ratio: Effect of sport and phase of training. J Strength Cond Res 20: 992-995, 2006.

38. Morgan, DW, Baldini, FD, Martin, PE, and Kohrt, WM. Ten kilometer performance and predicted velocity at $\mathrm{VO} 2 \mathrm{max}$ among well-trained male runners. Med Sci Sports Exerc 21: 78-83, 1989.

39. Morgan, DW, Bransford, DR, Costill, DL, Daniels, JT, Howley, ET, and Krahenbuhl, GS. Variation in the aerobic demand of running among trained and untrained subjects. Med Sci Sports Exerc 27: 404AU11 $409,1995$.

40. Morgan, DW and Craib, M. Physiological aspects of running economy. Med Sci Sports Exerc 24: 456-461, 1992.

41. Morgan, DW and Martin, PE. Effects of stride length alteration on racewalking economy. Can J Appl Sport Sci 11: 211-217, 1986.

42. Morgan, D, Martin, P, Craib, M, Caruso, C, Clifton, R, and Hopewell, R. Effect of step length optimization on the aerobic demand of running. J Appl Physiol (1985) 77: 245-251, 1994.
43. Nummela, A, Keranen, T, and Mikkelsson, LO. Factors related to top running speed and economy. Int J Sports Med 28: 655-661, 2007.

44. Nummela, AT, Heath, KA, Paavolainen, LM, Lambert, MI, St Clair Gibson, A, Rusko, HK, and Noakes, TD. Fatigue during a 5-km running time trial. Int J Sports Med 29: 738-745, 2008.

45. Osteras, H, Helgerud, J, and Hoff, J. Maximal strength-training effects on force-velocity and force-power relationships explain increases in aerobic performance in humans. Eur J Appl Physiol 88: 255-263, 2002.

46. Paavolainen, L, Häkkinen, K, Hamalainen, I, Nummela, A, and Rusko, H. Explosive-strength training improves 5-km running time by improving running economy and muscle power. J Appl Physiol (1985) 86: 1527-1533, 1999.

47. Paavolainen, L, Nummela, A, Rusko, $\mathrm{H}$, and Häkkinen, $\mathrm{K}$. Neuromuscular characteristics and fatigue during $10 \mathrm{~km}$ running. Int J Sports Med 20: 516-521, 1999.

48. Paavolainen, LM, Nummela, AT, and Rusko, HK. Neuromuscular characteristics and muscle power as determinants of $5-\mathrm{km}$ running performance. Med Sci Sports Exerc 31: 124-130, 1999.

49. Pate, RR, Macera, CA, Bailey, SP, Bartoli, WP, and Powell, KE. Physiological, anthropometric, and training correlates of running economy. Med Sci Sports Exerc 24: 1128-1133, 1992.

50. Raichlen, DA, Armstrong, $\mathrm{H}$, and Lieberman, DE. Calcaneus length determines running economy: Implications for endurance running performance in modern humans and Neandertals. J Hum Evol 60: 299-308, 2011

51. Saunders, PU, Pyne, DB, Telford, RD, and Hawley, JA. Factors affecting running economy in trained distance runners. Sports Med 34: 465-485, 2004

52. Scholz, MN, Bobbert, MF, van Soest, AJ, Clark, JR, and van Heerden, J. Running biomechanics: Shorter heels, better economy. $J$ Exp Biol 211: 3266-3271, 2008.

53. Spurrs, RW, Murphy, AJ, and Watsford, ML. The effect of plyometric training on distance running performance. Eur J Appl Physiol 89: 1-7, 2003.

54. Williams, KR and Cavanagh, PR. Relationship between distance running mechanics, running economy, and performance. $J$ Appl Physiol (1985) 63: 1236-1245, 1987.

55. Williams, KR, Cavanagh, PR, and Ziff, JL. Biomechanical studies of elite female distance runners. Int J Sports Med 8(Suppl 2): 107-118, 1987. 


\title{
AUTHOR QUERIES
}

\author{
DATE $\quad 10 / 31 / 2013$ \\ JOB NAME JSCR \\ ARTICLE JSCR-08-3875 \\ QUERIES FOR AUTHORS Barnes et al
}

\section{THIS QUERY FORM MUST BE RETURNED WITH ALL PROOFS FOR CORRECTIONS}

AU1) Please provide department or unit name in affiliation 1.

AU2) Please check the edit made in title.

AU3) Please note that the key words "submaximal aerobic capacity, biomechanics, and distance running" do not occur anywhere in the article. Please provide suitable replacements maintaining 3 to 6 key words.

AU4) Please provide the age ranges for all subjects mentioned in the Subjects section if you have not already. If any subjects were $<18$ years of age, please confirm that parental consent was obtained. Please also confirm, if you have not already, that informed consent documents were signed for all subjects.

AU5) Please provide manufacturer details (city) for the manufacturer "Polar Electro" in the sentence "Heart rate was determined...."

AU6) Please note that "confidence interval" has been changed to "confidence limit" in the sentence "There was a large positive..." Please check.

AU7) Please note that as per the journal style, subheadings are not allowed in "Discussion" section and hence have been deleted. Please check.

AU8) Please note that "and/or" construction is not allowed as per style. Hence, please reword "and/or" in the sentence "The relationship between..."

AU9) Please consider rephrasing the sentence "Previous studies completed..." for clarity.

AU10) Please note that original references 14 and 15 were identical. Hence, the repetition had been deleted and the references have been renumbered both in text and in list so as to maintain sequential order. Please check.

AU11) Please note that the references have been renumbered both in text and in list so as to maintain alphabetical order in the reference list, as per the style. Please check.

AU12) Figures 2 and 3 seem to be of poor quality. Please provide high resolution figures.

AU13) Please check the edits made to all the tables.

AU14) Please check the definition introduced for "CL" in Tables 2 and 3.

AU15) The citation of table footnotes " $\|$ and "” are missing inside the table. Please check and insert.

AU16) The citation of table footnote "|l" is missing inside the table. Please check and insert. 